\title{
IJTARP
}

International Journal of Transactional Analysis

$12(1), 3-17$

https://doi.org/10.29044/v12i1p3

Research \& Practice

This work is licensed under a

eative Commons Attribution 4 International License.

\section{The Game Grid}

\author{
(C) 2021 Stephen R. Lankton
}

\begin{abstract}
The author presents his own design of a Game Grid which can be overlaid on the original version of the circumplex attributed to Leary (1957). The original Interpersonal Check List (ICL) and associated axes and domains (sections) are retained as the purpose is to prompt individuals to explore their own behaviours and how these link to their life positions and the psychological games they may play. A short history of the ICL used is followed by the introduction of a modified OK Corral which recognises that there are some 'good' games, and a selection of psychological games is allocated to line up with the four major life positions. Appendices contain the materials, with links to other languages, and detailed instructions which will allow practitioners to apply the approach described. The author concludes with examples of how results may be interpreted and used to help individual clients and partners.
\end{abstract}

\section{Key Words.}

life positions, psychological games, OK Corral, Interpersonal Check List (ICL), game grid, circumplex,

\section{Introduction}

Many years ago (mid-1950s) an Interpersonal Check List (ICL) was developed, based on extensive research, and intended to assist in the classification of individuals into forms of psychiatric diagnoses. Since then, there have been several iterations of it, although the application described in this paper is based on an early version.

Within transactional analysis, Berne (1964) introduced the concept of psychological games and named many examples. He also introduced the notion of life positions (Berne 1962), which was subsequently developed into the OK Corral (Ernst 1971) as a way to illustrate four positions.

This paper describes how these initiatives have been further developed and combined to produce a process through which clients can be helped to identify the time spent by them in the various life positions, and the corresponding psychological games they 'play'.

\section{Interpersonal Check List}

The version of the ICL used as the basis for the Game Grid (IGG) described in this paper is the version published by Leary (1957). This book included a chapter which was credited as a reproduction with permission of a paper by LaForge and Suczek (1955). It was released by them as the Interpersonal Adjective Check List, as a measuring device for interpersonal behaviour. It is interesting to look back and see that it was already being administered 'technologically', albeit that it involved individuals sorting out cards into true or false piles, and these then being used as IBM punched cards (and described in a separate, unpublished paper by LaForge 1954).

Since then there have been many developments, including re-ordering the items, changing them to ensure even coverage of the domains that constitute the model, re-conceptualising the axes, and producing different instruments such as the Interpersonal Adjective Scales (IAS: Wiggins 1995), the Check List of Interpersonal Transactions (CLOIT: Kiesler, Goldston and Schmidt 1991) and the Support Actions Scale - Circumflex (SAS-C: Trobst, 2000).

When the original ICL was developed, there was a study with 30,000 subjects and it was found to correlate with the Minnesota Multiphasic Personality Inventory (MMPI) (Hathaway and McKinley 1940) although the MMPI has gone through several updates beginning in 1989. It also correlated with the Diagnostic and Statistical Manual of Mental Disorders (DSM) (American Psychiatric Association 1952) although that too has now gone through several updated iterations.

Those correlations were many years ago, and various norm tables have been produced using the subsequent iterations. However, norm tables were 
produced so that people could be compared in terms of their mental health. For the use described in this article, the focus is on individual differences. Use with clients has demonstrated that the 128 adjectival phrases lead to a self-report that will be recognised by clients as representative of their own self-image.

Scoring the version of ICL being presented here results in a circle graph as shown in Figure 1. The axes for these are Dominant versus Submissive and Affiliated/Friendly versus Disaffiliative/Hostile. There are eight domains: Managerial, Socially-Responsive, Cooperative, Dependent or Provoking Assistance, Self-Effacing, Rebellious or Provoking Hostile Rejection, Aggressive, and Competitive.

Scores result in shadings within the various domains, presenting a picture of how intensely each of the areas applies. Figure 2 shows several illustrations of how these might look for different clients.

\section{Life Positions}

Ernst (1971) produced the OK Corral as a visual representation of the four positions that had been written about by Berne (1962). He presented them using a vertical axis which refers to whether the other person is OK or not and a horizontal axis about whether the self is OK or not. He also focused on it representing social dynamics rather than Berne's original existential position, commenting that:

"1. There are dynamic operations going on in the person which can bring about a chosen resolution for himself, his inside view, and his view of the particular companion in each encounter.

2. There is a net outcome or resultant (measure) of the event by this person at the conclusion of the event." ( $p$. 33).

You will see later that this author has rotated the original axes so that the self-dimension becomes vertical and the other-person-dimension is now horizontal. This allows us to transpose it over the top of the ICL chart and correlate the understanding of the two conceptualizations.

A further modification is made in that a circle is cropped in the middle and included as part of the I'm OK, You're OK box, as shown in Figure 3. This is because it is healthy rather than psychologically gamy to be Disaffiliative or Submissive to varying degrees in some circumstances.

\section{Psychological Games}

Berne (1964) defined a game as "an ongoing series of complementary ulterior transactions, progressing to a well-defined predictable outcome" (p. 48). In that book he also wrote of what he referred to as 'good' games, although we might nowadays believe that these are more like pastimes because they do not include the switch or payoff which he added in his game formula (Berne 1972). They therefore appear within this model as within the OK-OK sector of the chart.
Disaffiliative Hostile

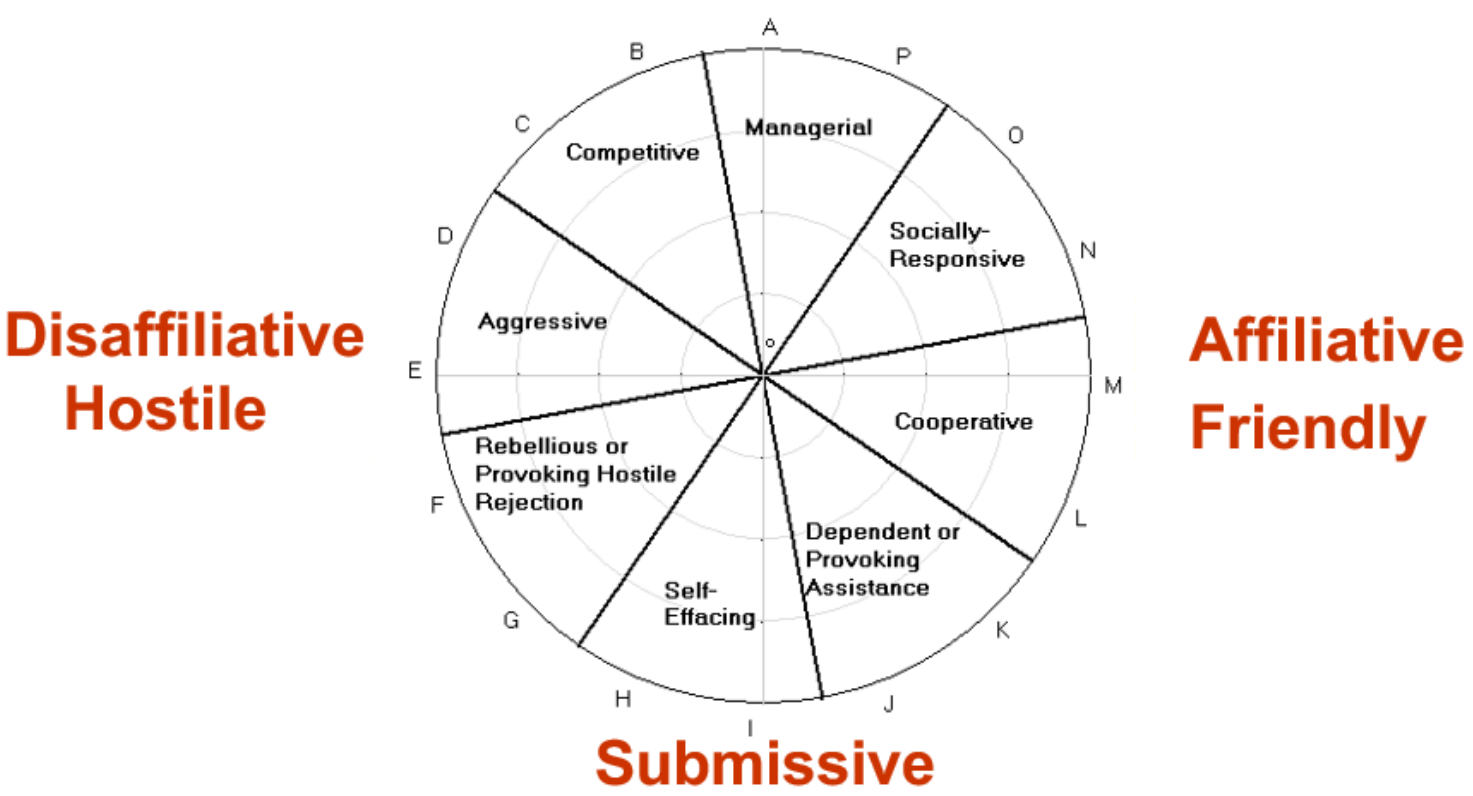

Figure 1: Interpersonal Check List Chart showing Axes and Domains 

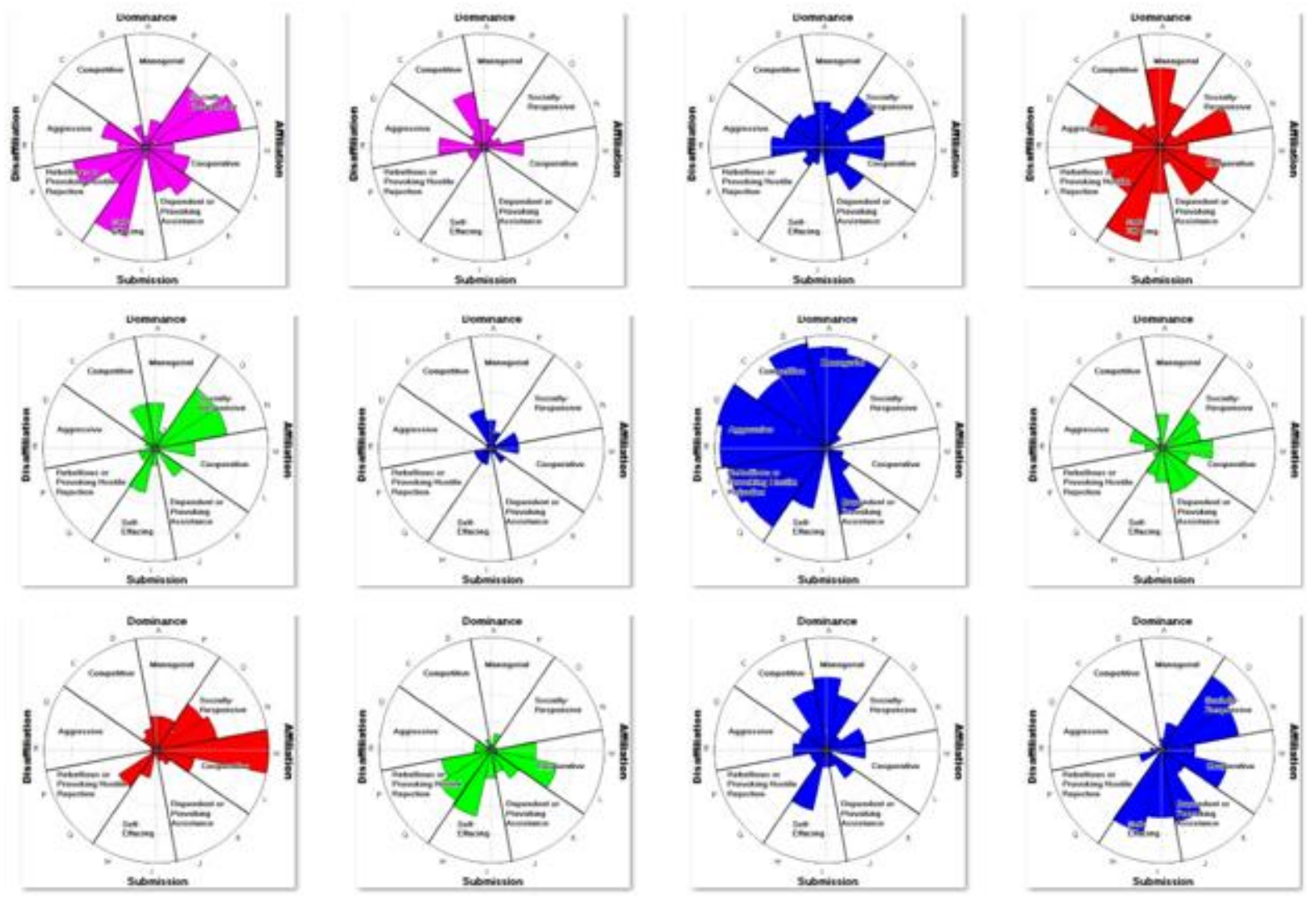

Figure 2: Thumbnail Illustrations of several Client ICL Charts

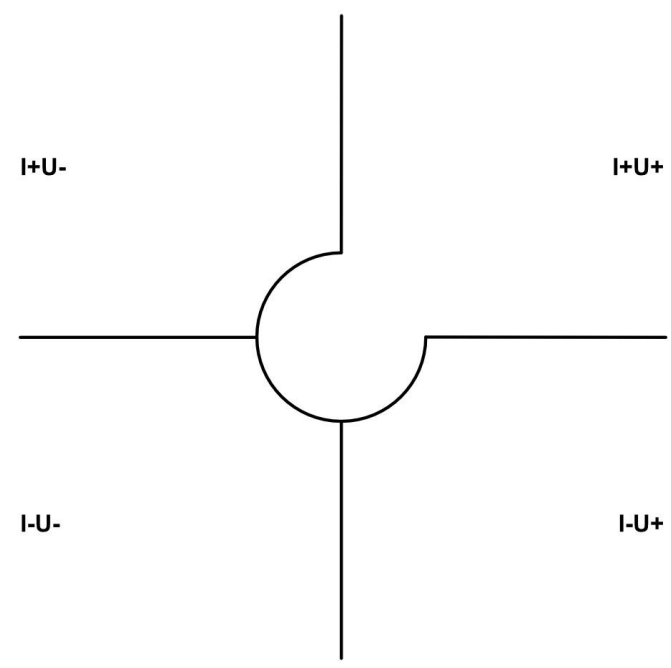

Figure 3: Modified OK Corral

Berne (1964) also wrote that "The most likely candidate of a systematic, scientific classification is probably one based on the existential position; but since knowledge of this factor is not yet sufficiently advanced, such a classification will have to be postponed. Failing that, the most practical classification at present is probably a sociological one." (p. 64). The GG is presented to begin doing just that - relating games to existential positions.

The Game Grid has been based on the behaviour and existential positions and includes a number of game names that I found to be most common with clients. There may of course be others that could be added. It does not of course incorporate ulterior behaviours such as voice tones or micro muscle movements which are usually unconscious. Clients will respond to the prompts from behaviours initiated from the various adjectival positions in terms of the using behaviour of which they are consciously aware. However, identification of the games being played will allow the client and practitioner to discuss the unconscious dynamics so that clients may become aware of them also.

Editor's Note: Berne used metaphorical names for games and some of these have become unacceptable nowadays. The author has therefore agreed that his material be amended so that NIGYSOB is renamed as Gotcha (Hay 1993), Wooden Leg becomes Millstone (Hay 1995), and Rapo, which he had renamed as Buzz off Buster becomes Rebuff (Hay 1993). We have also changed 'Let's you and him fight' to 'you and them' to avoid associating this game with one gender only. 


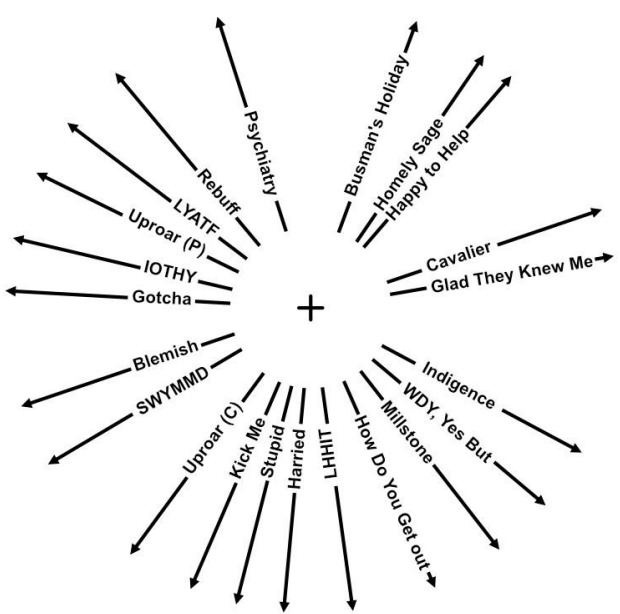

Figure 4: The Game Grid Overlay (shown larger in Appendix C)

For the benefit of those not familiar with the abbreviations used in the Game Grid: LYAHF is Lets You And Him Fight; IOTHY - I'm Only Trying To Help You; SWYMMD is See What You Made Me Do; LHHIT - Look How Hard I Tried; WDY is Why Don't You which is the other end of Yes But.

\section{Combining ICL, Life Positions and Psychological Games}

The process begins when the client completes the ICL, which is included as Appendix A. For each checkmark there is a weighted score to the left of the item. The weighted scores are then transferred onto the Scoring Sheet. These scores are then transferred into the circular chart shown in Figure 5, where the centre is zero, each hatch line represents one and the darker hatch lines represent five. Finally, the chart is shaded in line with the scores. This process is described in more detail in Appendix $B$; there is also an electronic version available, and the questionnaire has been translated into several languages - details are given in the Appendix.

In addition to the questionnaire, the practitioner needs to produce overlays from the modified OK Corral and from the Game Grid. These can be easily produced by printing the appropriate Figures onto overhead transparency acetates. The diagrams necessary to do this in corresponding sizes are included in Appendix C.

The modified OK Corral overlay is then put across the completed and shaded chart and the practitioner and the client can review what this illustrates in terms of the proportions of time spent by the client in the various life positions. This discussion can also include consideration of the meaning of the various domains.

Finally, the overlay of the GG can be added so that the client can become more aware of the games they are

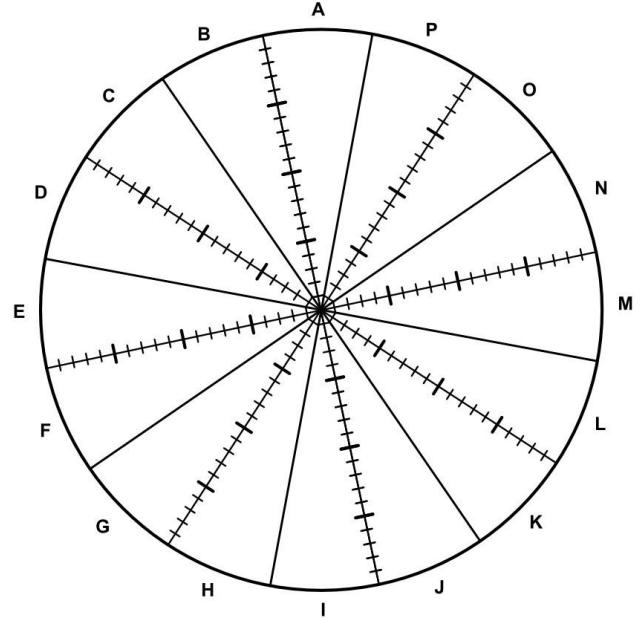

Figure 5: ICL Chart

playing, and how these will be the ways in which they have learned to behave in order to give and receive strokes and solve problems. It is of course possible to do this with two clients who are in relationship with each other. They might score for themselves and they might also score for each other.

\section{Interpreting the Results}

We can of course discuss with the client what the various domains represent, and explore the behavioural items they have checked. The underlying pattern may be seen when looking at the shadings of the various domains. For instance, a person may score high in $P$ but not in $A$, even though both of these represent Managerial behaviour. They may also score high in $\mathrm{N}$ but not in $\mathrm{O}$, even though both of these represent Socially Responsive behaviour. We might help the client to interpret that as meaning that they are willing to be managerial and responsive as long as they are not seen as being too domineering. $A$ and $O$ are more dominant forms of the managerial and socially responsive domains respectively. From a game perspective, this may mean that the individual's gimmick (Berne, 1966) is "I want to be in charge and helpful as long as you don't think I'm taking over." This would appear to be the individual's Achilles' heel, and would be worth exploring more carefully so the client can become aware of whether this is about not wanting to make people angry, or of being rejected by others, or of some other fear.

We might also review with the client where the major blocks of behavioural grouping are appearing, especially as they are likely to be contributing to failure to solve problems or get positive strokes. Noting which behaviours are being avoided may represent the impact of injunctions (Goulding and Goulding 1976) and the existing behaviours may comprise the substitute, or racket behaviours (English 1971, 1972). 
Note that some clients will not use the hostile behaviours that show up on the chart. Although they may have been checked on the questionnaire, the behaviours may be dormant in the current life context because those behaviours were learned in a previous, earlier environment and are no longer needed for obtaining strokes, or the client may have enough social control to avoid using them.

When the modified OK-Corral is overlaid on the chart, it shows that some clients will spend a percentage of time in different life positions rather than spending all of their time in one position. English $(1971,1972)$ posited that people may occupy more than one existential position, with one defensively covering another. In Figure 2 you can see there are a wide range of results that are possible. Hence, an individual may primarily get strokes from the OK-OK life position but play other games from a different position or positions.

When we overlay the Game Grid, we can link the games to the life positions they are played to reinforce. The grid includes my personal classification so the reader may wish to change these and to add more games. I have already explained that I have included some of Berne's 'good' games in the I'm OK, You're OK quadrant.

Continuing around the circle:

- I'm not OK, You're OK: the games here are Indigence; Why Don't You, Yes But; Millstone; How do you get out of here; and Look how hard I tried. Some are more submissive and are therefore closer to the bottom of the chart whilst others are friendlier and are closer to the righthand side.

- I'm not OK, You're not OK: this quadrant has more submissive games in lower positions, such as Harried; Stupid; Kick me. The more hostile games are further up, including Uproar; See what you made me do; and Blemish.

- I'm OK, You're not OK: this final top left quadrant contains behaviours for hostile-dominant behaviours so the games include Gotcha; I'm only trying to help you; Uproar; Let's you and them fight; Rebuff; and Psychiatry.

My placement of some of the games on the grid might be disputed. Berne and Stuntz (1971) both classified Kick Me as I'm not OK, although neither of them specified the 'You're' position. It might therefore be placed in both the bottom left and bottom right of the Grid - it is clearly Submissive but might be Affiliative or Disaffiliative. I have opted to place it just inside the bottom left to avoid visual clutter. Also, I have included Uproar twice because it can be played from the position of a dominant Parent ego state or a submissive Rebellious Child ego state. Sometimes an individual will alternate between both of these positions.

It might be argued that the information generated through this method is a self-report and therefore unreliable. In my clinical practice since 1974, I have rarely seen any form of deliberate deception. Clients have voluntarily come for help and will therefore do their best to provide accurate information. Since this self-report is a client's self-image, occasionally it can be inaccurate or distorted. It can sometimes be useful to have someone else score the client as well. When working with clients who are partners, it can be useful for them to score themselves and to also score their partner. In that way, the review can cover their perceptions of each other as well as how their patterns may or may not reinforce each other.

\section{Conclusions}

I first conceived the Game Grid and developed it in the early 1980 s, using a paper version. I am delighted that technology now allows us to distribute it to a wider audience, both through this journal and through the website mentioned in Appendix B.

I have been teaching the use of it in workshops for many years as well as using it with all of my clients. Because the ICL is the client's own self-report, the existence of the behaviours indicated in each section provide a bridge to increase their awareness of their life positions and the games they are playing. It is much easier to gain the clients acceptance and recognition when it is based on their own self-report. The results can also be linked easily to their strokeseeking behaviour, and it forms a helpful step in involving their Adult ego state in the process of their own development.

Stephen Lankton, Licensed Clinical Social Worker, Diplomate American Hypnosis Board, Fellow American Society of Clinical Hypnosis, is an Emeritus Clinical Member of ITAA due to having been involved with TA for so many years. He can be contacted on steve@lankton.com.

\section{References}

Association, A. P. (1952). Diagnostic and statistical manual of mental disorders (2nd ed.). American Psychiatric Association. https://doi.org/10.1176/appi.books.9780890425596

Berne, E. (1962). Classification of positions. Transactional Analysis Bulletin, 1(3), 23.

Berne, E. (1964). Games People Play. Grove Press.

Berne, E. (1966). Principles of Group Treatment. Oxford University Press.

Berne, E. (1972). What Do You Say After You Say Hello? Grove Press. 
English, F. (1971). The substitution factor: rackets and real feelings, part 1. Transactional Analysis Journal, 1(4), 225-230.

https://doi.org/10.1177/036215377100100408

English, F. (1972). Racket and real feelings, part 2. Transactional Analysis Journal, 2(1), 22-25. https://doi.org/10.1177/036215377200200108

Ernst, F. H. (1971). The OK corral: The grid for geton-with. Transactional Analysis Journal, 1(4), 33-42. https://doi.org/10.1177/036215377100100409

Goulding, R., \& Goulding, M. (1976). Injunctions, Decisions and Redecisions. Transactional Analysis Journal, 6(1), 41-48.

https://doi.org/10.1177/036215377600600110

Hathaway, S. R., \& Mckinley, J. C. (1940). A multiphasic personality schedule (Minnesota): I. Construction of the schedule. Journal of Psychology, 10, 249-254.

https://doi.org/10.1080/00223980.1940.9917000

Hay, J. (1993). Working it Out at Work. Sherwood Publishing.

Hay, J. (1995). Donkey Bridges for Developmental TA. Sherwood Publishing.
Kiesler, D. J., Goldston, C. S., \& Schmidt, J. A. (1991). Manual for the Check List of Interpersonal Transactions - Revised (CLOIT-R) and the Check List of Psychotherapy Transactions - Revised (CLOPT$R)$. Virginia Commonwealth University.

Laforge, R., \& Suczek, R. F. (1955). The interpersonal dimension of personality: An interpersonal check list. Journal of Personality, 24, 94-112.

Leary, T. (1957). Interpersonal Diagnosis of Personality: A Functional Theory and Methodology for Personality Evaluation. John Wiley \& Sons. https://doi.org/10.2307/2390609

Stuntz, E. (1971). Classification of games by position. Transactional Analysis Journal, 1(4), 57-60. https://doi.org/10.1177/036215377100100413

Trobst, K. K. (2000). An interpersonal conceptualization and quantification of social support transactions. Personality and Social Psychology Bulletin, 26, 971-986. https://doi.org/10.1177/01461672002610007

Wiggins, J. S. (1995). Interpersonal Adjective Scales: Professional Manual. Psychological Assessment Resources. 
Name:

Date:

Instructions: Place a check mark $\square$ by the phrases which describe or apply to you, whether you engage in the behaviour frequently or only occasionally.

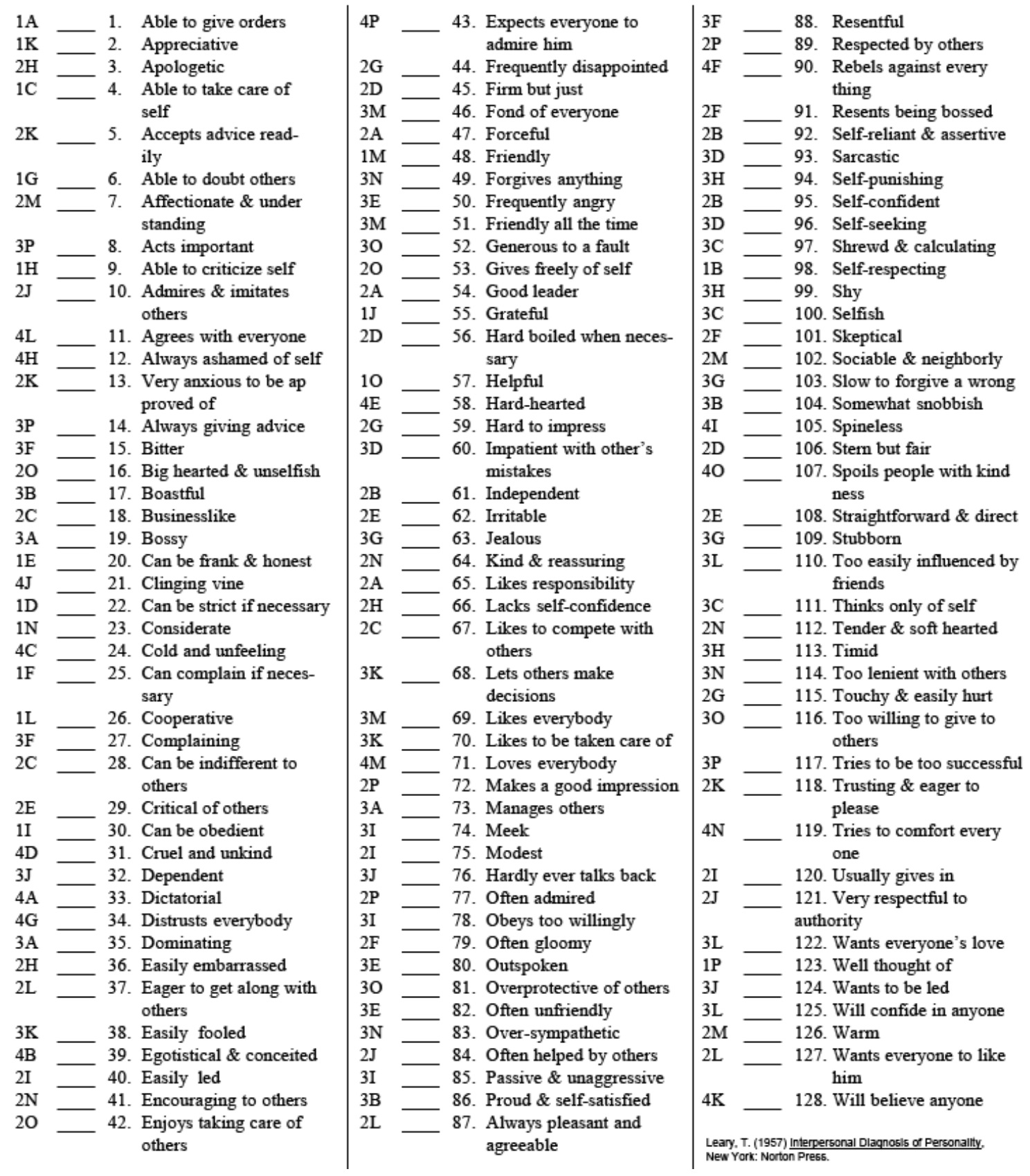




\section{Appendix B: Scoring the ICL}

There is an electronic version for administration and scoring of the ICL. This program is free-of-charge. It was written by Dr. Shawn Lankton, Ph.D., and can be downloaded from: https://lankton.com/icl.zip. The executable file found within the ZIP file is compatible with all versions of Windows (32 or 64-bit architecture). All necessary instructions are included. There may be one additional short installation step necessary for some users -- which is clearly explained. In addition, there are several paper versions included in the ZIP file (the Check List is available now in English, French, Czech, German, Japanese, Portuguese, and Spanish).

The following describes the process of scoring the paper version, and also explains the graphing process so that those who are not using the electronic version understand how to administer it.

When completed, the entire scoring sheet will look like the following diagram. Each weighted score to the left of each item consists of the numbers 1 through 4 and the alphabetical character A through $\mathrm{P}$.

\begin{tabular}{|c|c|c|c|c|c|c|c|c|}
\hline $1 \mathrm{~A}$ & 1. & Able to give orders & & & admire him/her & $2 F$ & 91. & Resents being bossed \\
\hline $1 \mathrm{~K}$ & 2. & Appreciative & $2 \mathrm{G}$ & 44. & Frequently disappointed & $2 \mathrm{~B}$ & 92. & Self-reliant \& asser- \\
\hline $2 \mathrm{H}$ & 3. & Apologetic & (20) $\sqrt{2}$ & 45. & Firm but just & & & \\
\hline $1 \mathrm{C}$ & 4. & Able to take care of & $3 \overrightarrow{\mathrm{M}}$ & 46. & Fond of everyone & $3 \mathrm{D}$ & 93. & Sarcastic \\
\hline & & self & $2 \mathrm{~A}$ & 47. & Forceful & $3 \mathrm{H}$ & 94. & Self-punishing \\
\hline $2 \mathrm{~K}$ & 5. & Accepts advice readily & $1 \mathrm{M}$ & 48. & Friendly & $2 \mathrm{~B}$ & 95. & Self-confident \\
\hline & 6. & Able to doubt others & $3 N$ & 49. & Forgives anything & $3 \mathrm{D}$ & 96. & Self-seeking \\
\hline & 7. & Affectionate \& under & $3 \mathrm{E}$ & 50. & Frequently angry & $3 \mathrm{C}$ & 97. & Shrewd \& calculating \\
\hline & & standing & $3 \mathrm{M}$ & 51. & Friendly all the time & $\mathbb{B}$ & 98. & Self-respecting \\
\hline $3 \mathrm{P}$ & 8. & Acts important & 30 & 52. & Generous to a fault & $3 \mathrm{H}$ & 99. & Shy \\
\hline $1 \mathrm{H}$ & 9. & Able to criticize self & 20 & 53. & Gives freely of self & $3 \mathrm{C}$ & 100. & Selfish \\
\hline $2 \mathrm{~J}$ & 10. & Admires \& imitates & $2 \mathrm{~A}$ & 54. & Good leader & $2 F$ & 101. & Skeptical \\
\hline & & others & $1 \mathrm{~J}$ & 55. & Grateful & $2 \mathrm{M}$ & 102. & Sociable \& neigh- \\
\hline $\mathbb{4}$ & 11. & Agrees with everyone & $2 \mathrm{D}$ & 56. & Hard boiled when & & & borly \\
\hline $4 \mathrm{H}$ & 12. & $\begin{array}{l}\text { Always ashamed of } \\
\text { self }\end{array}$ & 10 & 57. & $\begin{array}{l}\text { necessary } \\
\text { Helpful }\end{array}$ & $3 \mathrm{G}$ & 103. & $\begin{array}{l}\text { Slow to forgive a } \\
\text { wrong }\end{array}$ \\
\hline $2 \mathrm{~K}$ & 13. & Very anxious to be & $\mathbb{4 E}$ & 58. & Hard-hearted & $3 \mathrm{~B}$ & 104. & Somewhat snobbish \\
\hline & & approved of & $2 \mathrm{G}$ & 59. & Hard to impress & 41 & 105. & Spineless \\
\hline 3P & 14. & Always giving advice & $3 \mathrm{D}$ & 60. & Impatient with other's & $2 \mathrm{D}$ & 106. & Stern but fair \\
\hline $3 \mathrm{~F}$ & 15. & Bitter & & & mistakes & 40 & 107. & Spoils people with \\
\hline 20 & 16. & Big hearted \& unsel- & $2 \mathrm{~B}$ & 61. & Independent & & & kindness \\
\hline
\end{tabular}

The weighted scores (1 thru 4) are transferred to the appropriate line in the columns shown in the following illustration. The column has individual lines for letters A-P. So, if a score shows as $1 \mathrm{~A}, 1$ should be placed on the line for $A$. In the limited example shown below, the hypothetical person $A 1,2 D, 10$, and both $2 M$ and $1 M$. Those five items are recorded in the lines of the first column on the scoresheet shown below.

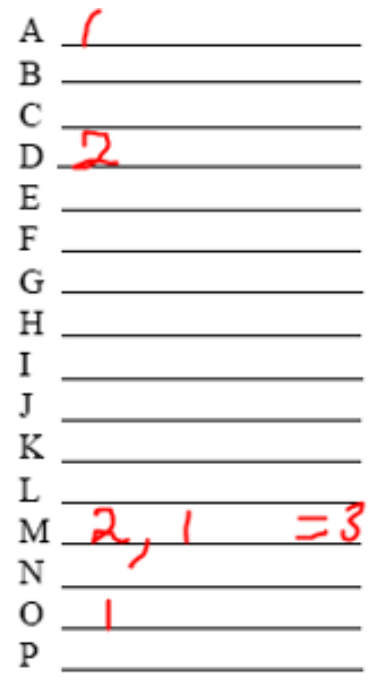


The weighted scores on each line are then added together and this totalscore is transferred onto the circular graph, in which the centre is zero and each line represents a score of 1 , with the more prominent lines representing a score of 5 .

The example below is based on a completed checklist for a hypothetical client. Each line has been totalled and that total is indicated in the circular chart at the appropriate point. Note that the image depicts a bar across each corresponding segment.

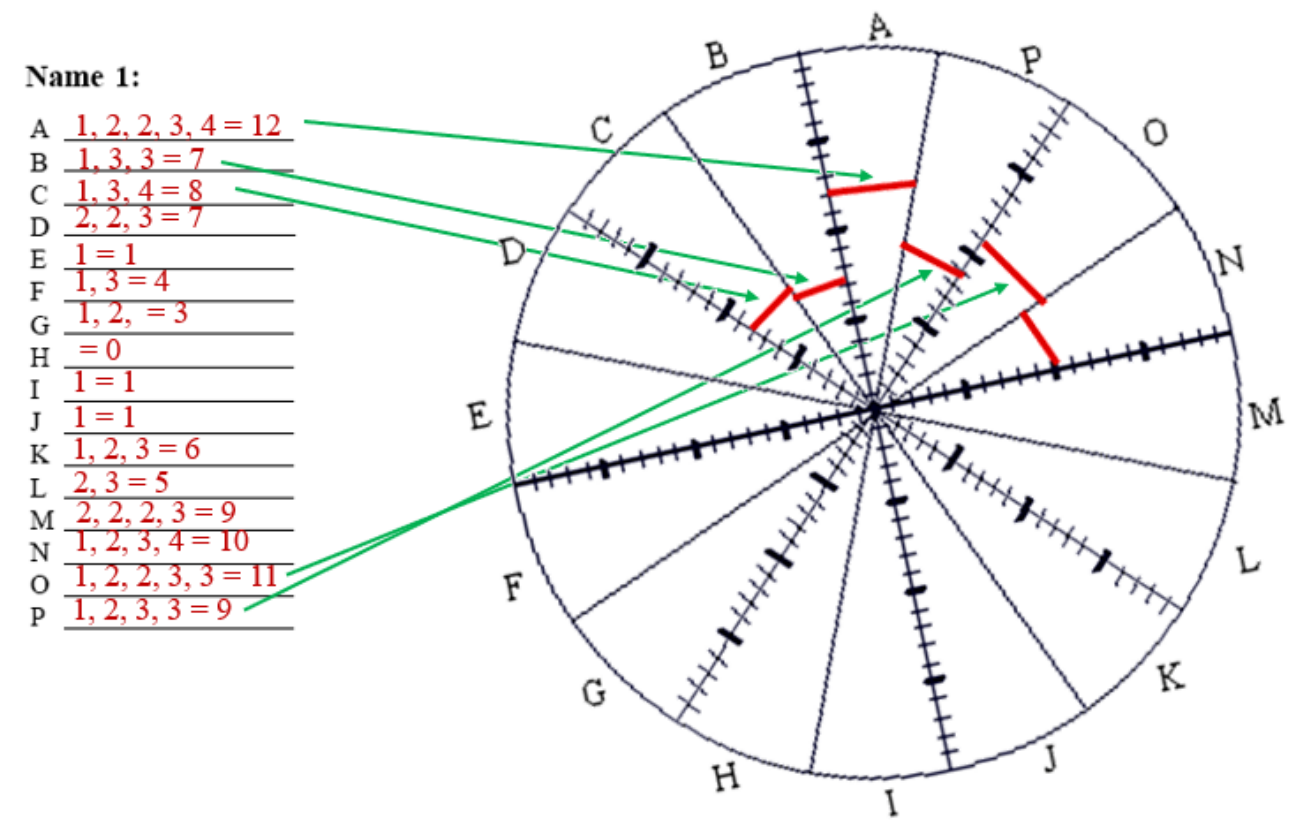

The various segments or domains can then be shaded in so that it is easier to see the pattern, as shown below. This creates a circular bar-graph. Each segment is a bar rising from the centre point of the circle.

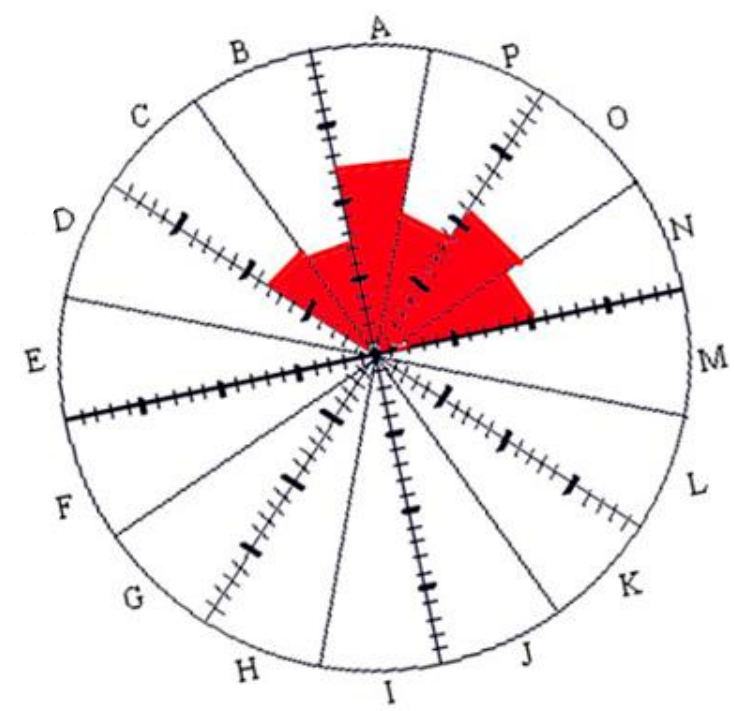

It will be seen that this chart would represent a person whose self-report shows that most of their behaviours are dominant, and much of their behaviour is affiliative, e.g., friendly.

Another example is shown below to illustrate how this can then be shown to the client in a way that includes the axes and the domains. 


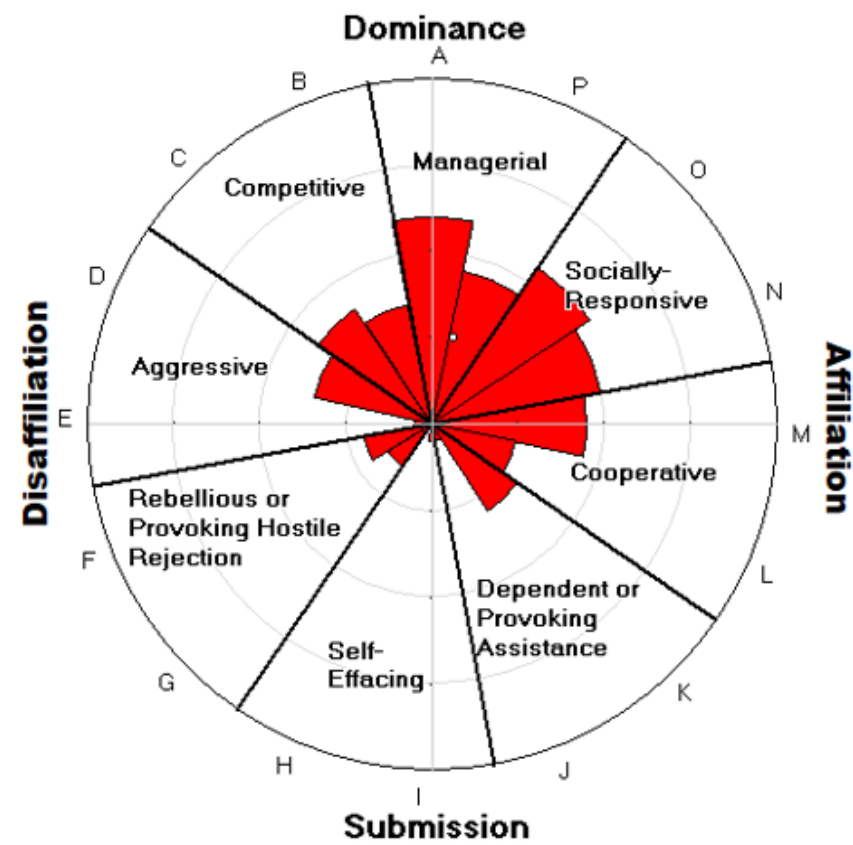

This can then be overlaid with the modified OK Corral diagram, as follows.

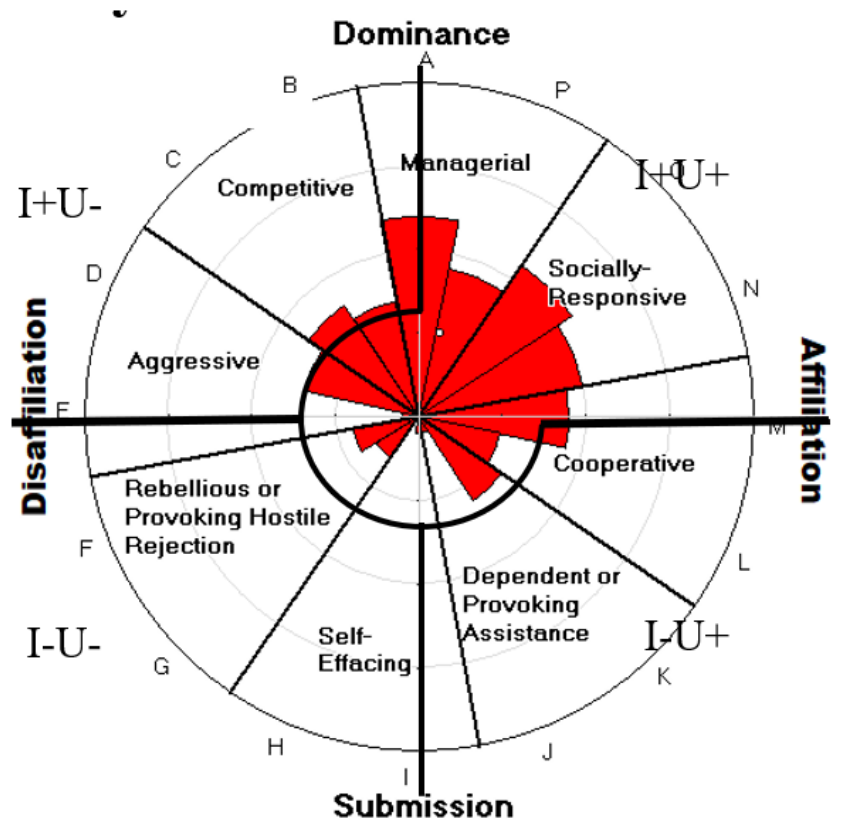

From the above example it can be concluded that the subject the graph represents is likely to primarily transact from an I'm Ok, You're OK life position. 


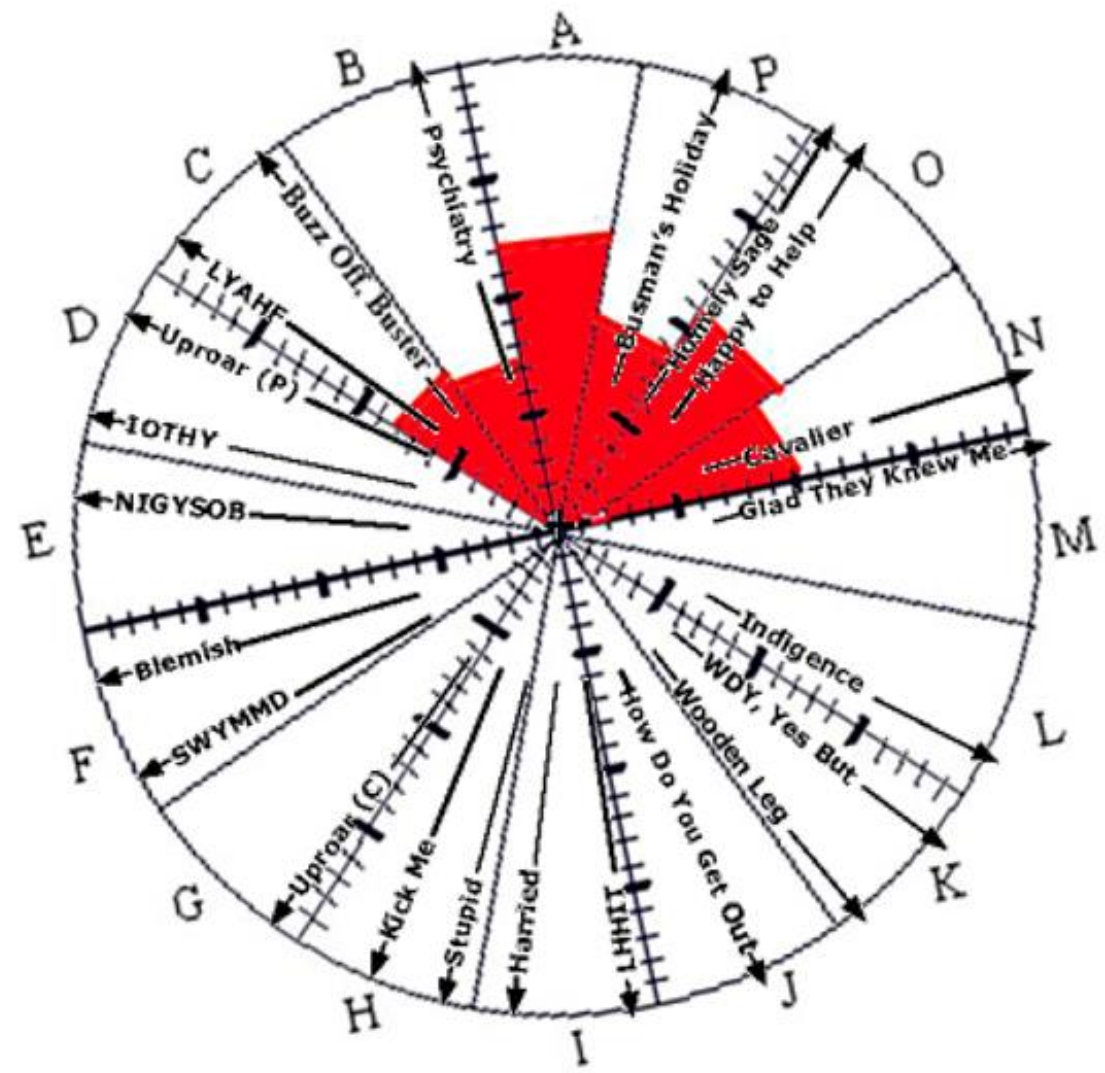




\section{Appendix C: Diagrams to print out}

Note: these diagrams have been produced to the same size so the domains, life positions and games can be printed out onto acetate sheets and overlaid onto the client's graph printed out on paper.

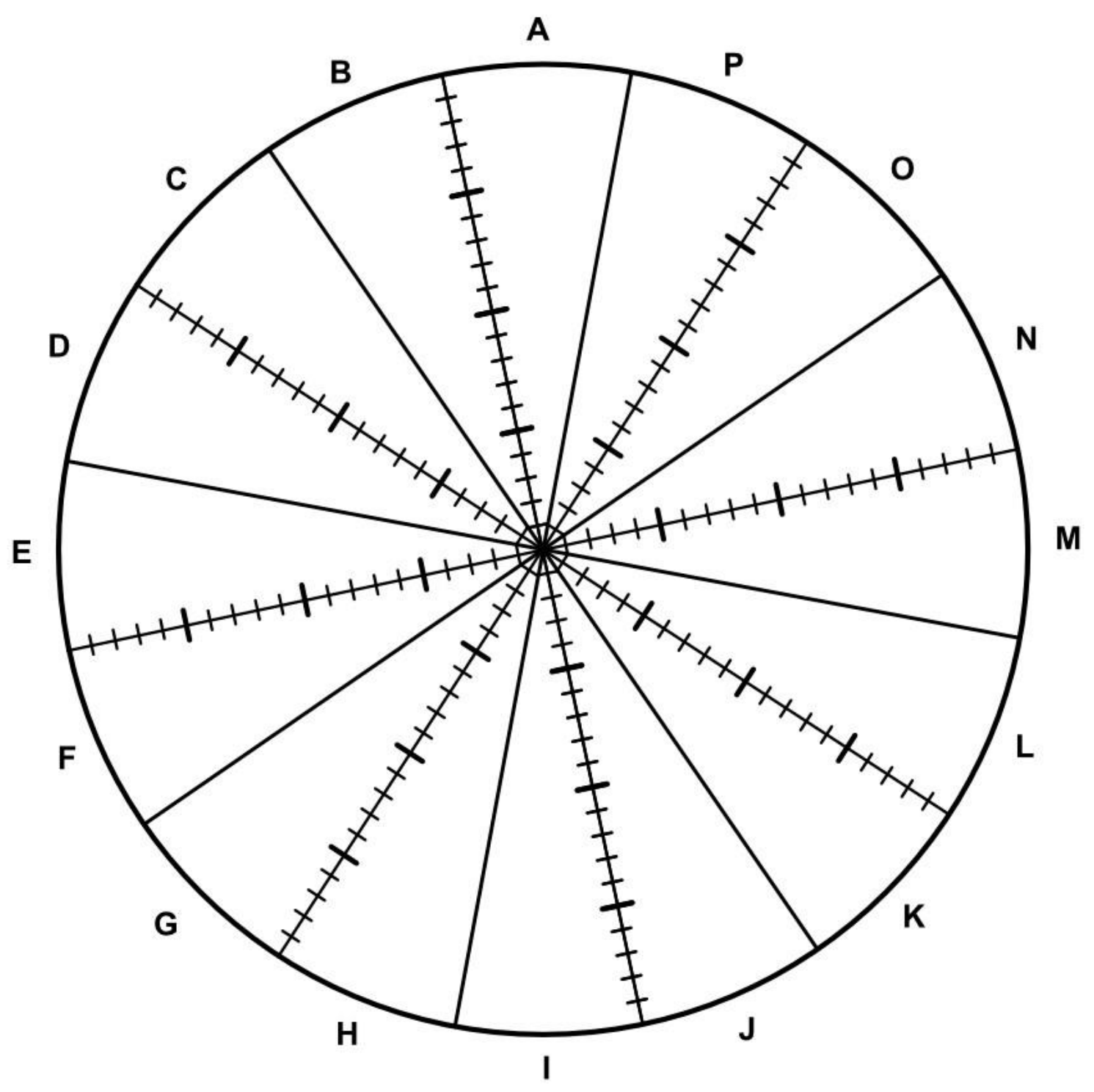




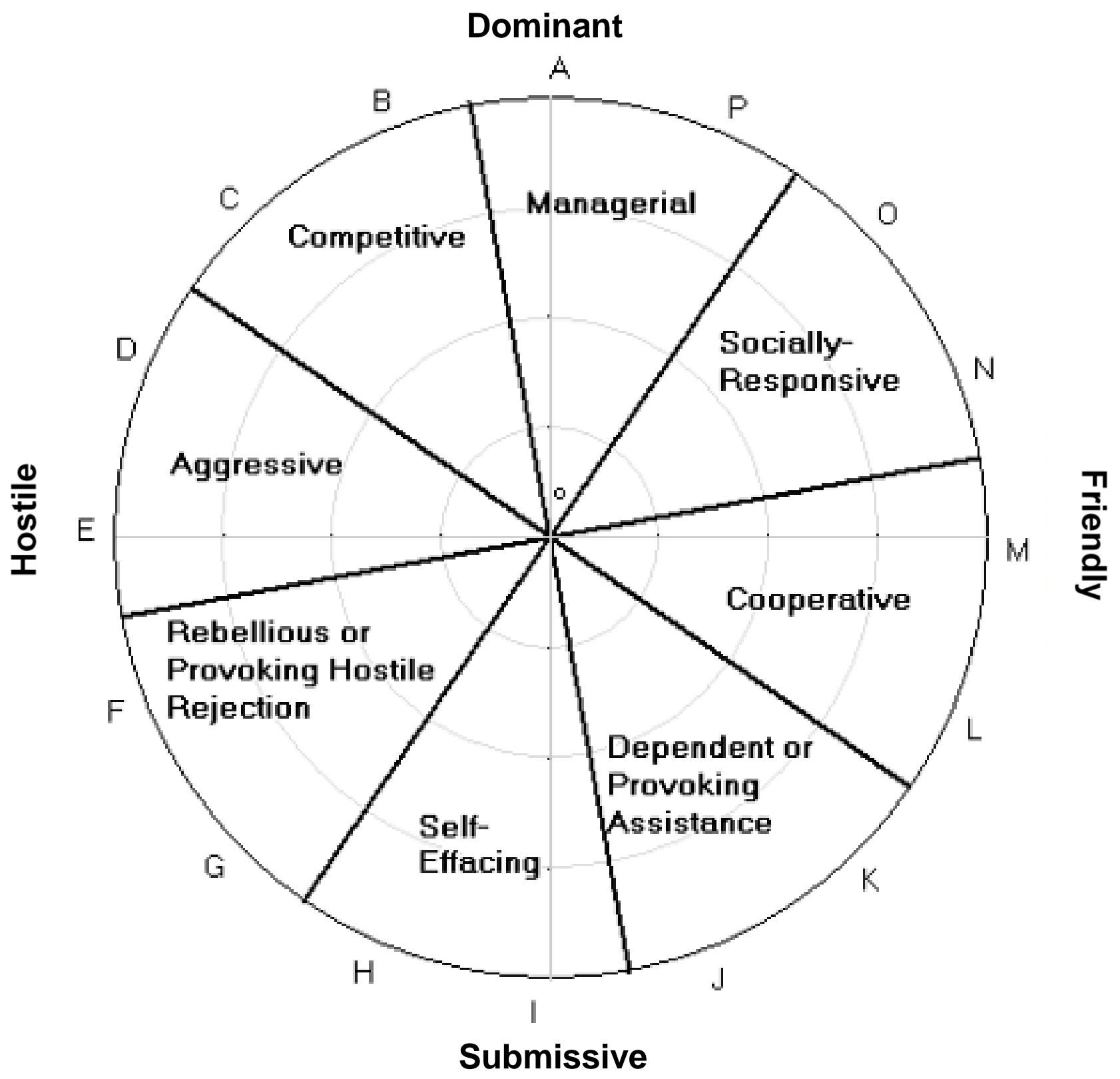




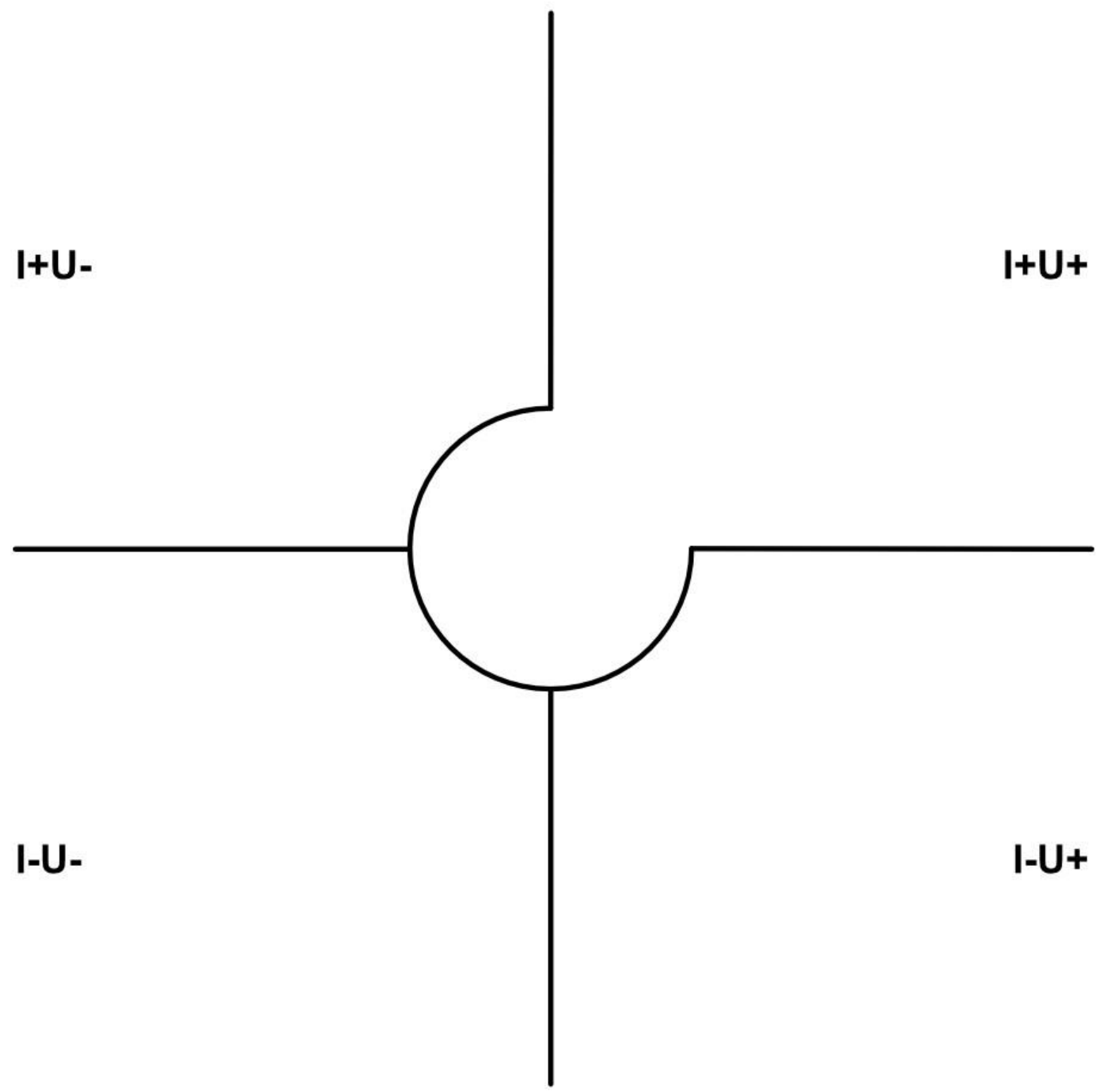



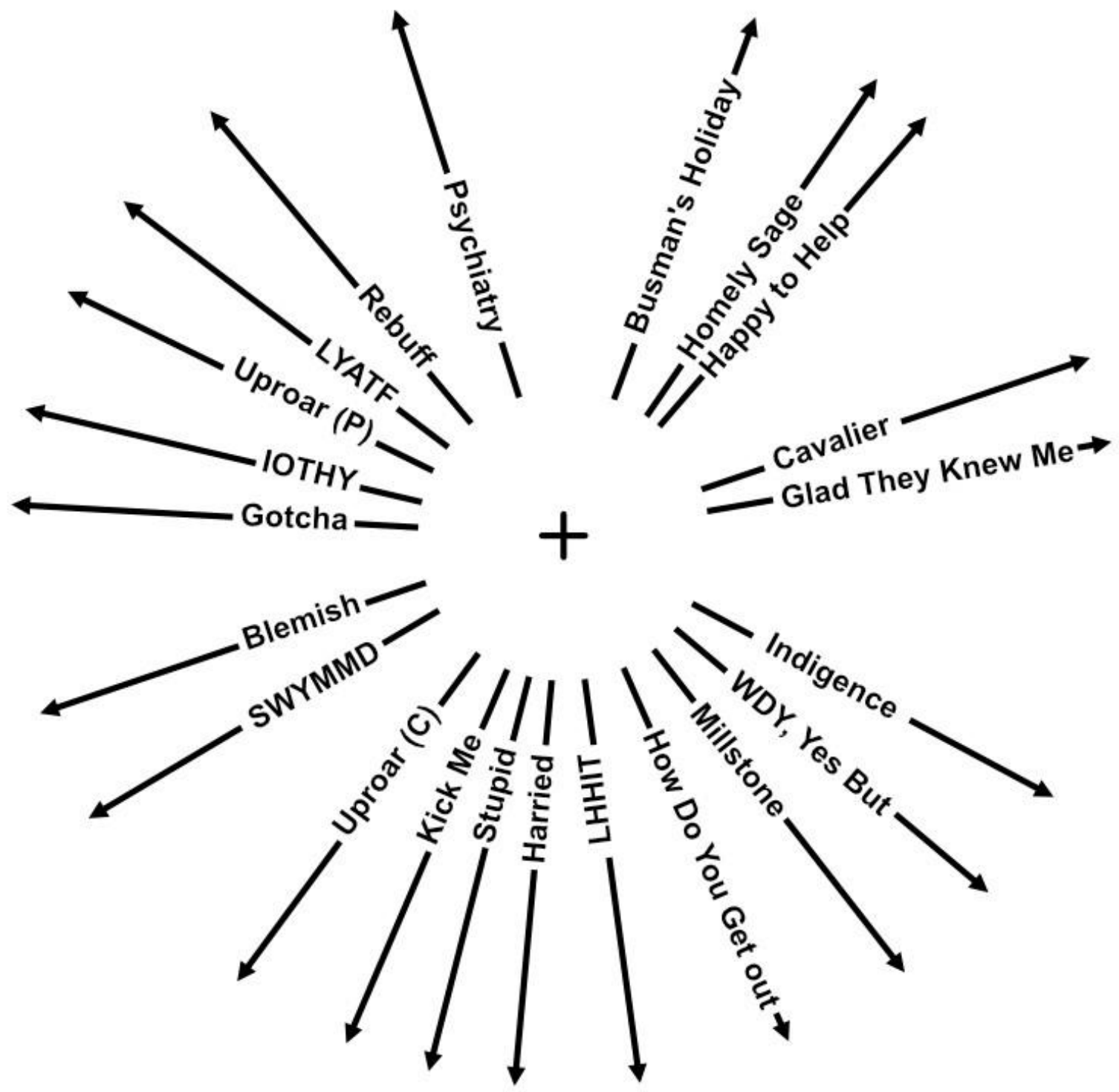